\title{
The Formation of Values of Education in the Mathematics Teachers of the Future in the Process of Adaptation into University Study
}

\author{
Rashida G. Gabdrakhmanova \& Anvar N. Khuziakhmetov \\ Kazan (Volga region) Federal University, RUSSIA \\ Ulzhalgas A. Yesnazarova \\ Republican Institute for development of leading, KAZAKHSTAN
}

•Received 17 June $2015 \bullet$ Revised 22 August $2015 \bullet$ Accepted 19 September 2015

\begin{abstract}
The topicality of the problem is in the fact that the applicant - future teachers of mathematics - has a value of education which is only partially formed. This will affect the adaptation of first-year higher education students. The article reveals the necessity for theoretical basis of the educational values' formation of first-year students who are set to become future teachers of mathematics. The leading method in the study of this problem is experiment. As a result of pedagogical experiment, the first-year students' level of educational value begins to increase. Students evaluated the need for interaction, selfesteem, education, and the importance of motive to scientific activities. Materials from this article may be useful for the curators of student groups, high school teachers and heads of departments. These materials can be used in their work with first-year students of higher educational institutions, as well as for researchers in organizing and conducting experiments on the problem within a higher educational institution.
\end{abstract}

Keywords: adaptation, values, education, student

\section{INTRODUCTION}

\section{The topicality of the problem}

The topicality of the selected problem is caused by changes in the social, economic and spiritual spheres of society, especially in the changing values of social priorities that have a significant impact on the development of education. These trends are reflected in the most important regulations that reflect the state educational policy of the Russian Federation. Formation of the theory and practice of modern university education is considered by Plaksiy (2007). Questions of education and training of today's students are presented in the study of Ilynsky (2011). In the ethical teachings of the past, a large number of concepts of morality were overviewed. There were

Correspondence: Anvar N. Khuziakhmetov,

Kazan (Volga region) Federal University, Kremlyovskaya Street, 18, Kazan, 420008, Russia.

E-mail: hanvar9999@mail.ru

doi: 10.29333/iejme/297 
values, attempts to describe, explain and introduce the word "morality" in general. The provisions of the awareness of the concept of "value" and its qualified characteristics in a changing system of values can be seen in the works of famous philosophers.

One of the important tasks of the university is to work with first-year students. This work has to be aimed to a more rapid and successful adaptation to the new system of training, to a new system of social relations, and to the development of their new role as higher education students. In the adaptation of students to study at university, all participants in the educational process have an interest in: themselves as students, teachers and their colleagues who work with them, and the management and university faculty (Nigmatov, 2014). It is a known fact that values are important factors influencing mans' desires and actions (Khuziakhmetov, 2004). Retrospective analysis of scientific literature showed that the hierarchy of values varied according to the level of cultural and socio-political development of society (Khuziakhmetov, 2009). Specificity of educational values is a vital position of the person. This position is based on a combination of the following values: educational dialogue, knowledge and the values of scientific inquiry. The participants of educational dialogue are able to think collectively and it is assumed that one answer is enriched at the expense of another. The value of knowledge has a social nature; it is regarded as the acquisition of knowledge, and comprehension of the laws of the objective world. The value of scientific research is characterized by a willingness of students to solve issues through professional methods of scientific investigation. Values play an important role in the formation of person - a member of society (Yarullin \& Nasibullov, 2014), performing two main functions: being the basis for the formation and saving the value of orientation in people's minds, they allow the individual to take a stand, to find a point of view, to assess; The value motivates activities and behavior, because the orientation of the human in society and the aspiration of individual goals correlates with the values, which are included in the structure of the person (Khuziakhmetov \& Gabdrakhmanova, 2011). The mechanism of action and the development of values associated with the necessity of resolving the contradictions and conflicts in the motivational sphere of human aspirations (Gabdrakhmanova \& Egereva, 2012). An important place in the system of values of first-year students should be taken by the value of education, because first-year students must realize the importance of the acquired knowledge and skills are a necessity of quality education (Khuziakhmetov, 2005).

\section{Explore importance of the problem}

In the modern theory and practice of higher education, the formation of educational values of first-year students who will become future teachers of mathematics, have not received attention as to the process of adaptation to studying at university. There is a need for the formation of these values, the need to pay attention to the work of university instructors, as well as the work of curators. Scientific search for a solution to the problem of formation of educational values that are aimed at resolving the contradictions between the need to develop values education of first-year students, future teachers of mathematics, and a lack of theoretical and methodological elaboration question the following: The need to create a single image of the university as a community of teachers, curators and students and some of their disunity; and the presence of a rich cultural potential of academic disciplines in shaping the values of education and insufficient development of guidelines, as well as their inclusion in the educational process. We formulated the following research problem: How to model and implement the formation of educational values of first-year students, future teachers of mathematics, in the process of adaptation to study at university. 


\section{Features of formation of values of education}

The formation of educational values of first-year students, future teachers of mathematics, during the process of adaptation to study at university is based on a number of general didactic principles. On the basis of the age of first-year students, as well as the state of the education sector and education requirements, the following principles are accepted: humanistic, personalities, continuity of development, and perspectives.

\section{Status of a problem}

To solve the selected problem, we considered the following scientific studies: the establishment of the theory and practice of modern university education; the study of the emotional sphere of personality in the educational process; studies, considered as a subject and a student and teacher of high school; research in the field of social adaptation in an educational institution.

The analysis of these works, and analysis of many other publications in this topic showed that the questions relating to the study of the formation of educational values has not been sufficiently studied and this has led to the development of problems of conceptual ideas.

\section{Research of the hypothesis}

We formulated the hypothesis of the study: The formation of educational values of first-year students, future teachers of mathematics, in the process of adaptation to studying in universities will be effective if: the conditions, which is conducive to the formation of educational values will be implemented; we will be guided by a scientifically based model of the formation of educational values in first-year students, future teachers of mathematics; and apply criterion-diagnostic apparatus of formation of educational values.

\section{MATERIALS AND METHODS}

\section{Objectives of the study}

This research solves the following objectives: 1) How to study the evolution of values in historical and philosophical, psychological and pedagogical literature; 2) The identification of indicators and levels of formation of values of education in firstyear students, future teachers of mathematics; 3 ) The identification of conditions for the successful formation of values of education in first-year students in the process of adaptation to studying in university; 4) The choice of the experimental and control groups of students; 5) Undertaking educational work with the students in the experimental group, considering a chosen system of conditions, doing educational work with the students in the control group; and 6) Analysis of the results of the experimental work, evaluating the effectiveness of the system.

\section{Theoretical and empirical methods}

In order to check the hypothesis, a complex of different methods that each complement one another, has been employed:

Theoretical methods: Theoretical analysis and synthesis of philosophical, methodological, pedagogical, psychological, sociological and scientific literature, synthesis, comparison, and modeling;

Empirical methods: The study of teaching and program documentation, organizational and regulatory documents, observation, questioning, discussion, pedagogical experiment, qualitative and quantitative analysis of the experimental results, and statistical and mathematical methods. 


\section{Base of research}

The basis of the study was the Institute of Mathematics and Mechanics, at Kazan (Volga) Federal University.

\section{Stages of the study}

The study was conducted in three stages:

The first stage was devoted to understanding the formation and problems, aims and hypotheses of the study, the development aims and work plan in order to determine the general concept of the study. At this stage, the analysis and synthesis of philosophical, pedagogical, psychological and methodological literature on the study was carried out.

The second stage was to develop the base of the research. The conditions for the formation of educational values were determined, and the indicators and levels of educational values formation of first-year students were defined for future teachers of mathematics within the period of adaptation to studying at university, as well as the conditions which ensure their effectiveness. Refined and adjusted, the research program conducted a pedagogical experiment; then, the results were analyzed.

In the third stage qualitative and quantitative processing of the results and their theoretical underpinnings, systematization and generalization of the results of theoretical and experimental studies were carried out. Then, the main conclusions of the work were formulated.

\section{Evaluation criteria}

Evaluation of the effectiveness of the conditions was made based on the following criteria:

- the level of student interaction - as an indicator of the value of dialogue in education;

- the level of self-esteem of the student - as an indicator of the value of knowledge;

- the level of demand for education and motivation in science - as an indicator of the value of scientific research.

\section{Proceedings and description of the experiment}

In the process of ascertaining experiment diagnostics, the level of formation of educational values of first-year students, future teachers of mathematics, was conducted. In the experiment, the state of the educational process, the work plans of the curators for the purpose of determining the place of educational values in the interaction of the subjects of the educational process, were examined (Zaripova et al., 2015). During the monitoring of the learning process and extra-curricular activities of students, we found that the content is not sufficiently directed to the formation of values of education in first-year students, future teachers of mathematics. It should be noted, however, that the subject of supervisory hours for self-development and self-education does not fully affect the formation of educational values (Khuziakhmetov, 2011).

The content of the subjects studied as the first course at university, is not sufficiently directed to the formation of educational values. Studying programs for the first course have fragmentary material on one of the values of education, especially on the value of the educational dialogue. The theme of curators' hours for selfdevelopment and self-identity of first-year students does not fully affect the formation of educational values.

Nowadays, scientific literature mentions eight values of education. According to the diagnostics results, we found values that the least important values for first-year students are self-development (36\%) and the value of their own individuality (55\%). 
Table 1. Indicators of values education

\begin{tabular}{ll}
\hline Values of Education & Indicators \\
\hline The value of the educational dialogue & Interaction, expression of emotions and feelings \\
The value of knowledge & Self-esteem \\
The value of scientific research & Need for education, motivation in science \\
\hline
\end{tabular}

First-year students, future teachers of mathematics, preferred values such as high financial situation (92\%) and their own prestige (69\%).

On the basis of the identified indicators, we characterized the following level of development of educational values: high level, average level, low level (Table 1).

During the experiment, we selected diagnostic techniques for identifying baseline values of education by finding the average number of the selected values. We used the following methods for the diagnosis: conversation, questioning and observation, etc.

In the process of the experiment, work has focused on the formation of a complex educational dialogue, values and knowledge of the value of scientific research, which together make up the value of education. The basis of the experimental work was built on the idea that the efficiency of the formation of educational values in first-year students, future teachers of mathematics, in the process of adaptation to studying at university, includes the following conditions: a purposeful formation of educational values in the educational process of university; inclusion in the process of adapting of the various forms of work with students (discussion, lecture, seminar, conference, contest etc.), (Khuziakhmetov, 2006); the level of students' awareness of their achievements (Khusainova, Chirkina, \& Gabdrakhmanova, 2015); and the activation of the closest social environment of students (Nigmatov, 2015). This formative experiment showed that in the process of adaptation of first-year students, future teachers of mathematics, there took place a change of educational values.

\section{RESULTS}

\section{Studying Process}

We proposed the following adjustments in the learning process: classroom teachers were recommended to focus their attention on the culture of speech of students and teachers emotions; and to consider options for business communication. This is actively implemented in the discipline called "Introduction to the pedagogical activity". Teachers in the classroom included all students in active interaction, giving them a chance at advancement. This contributed to the formation of the educational value of dialogue, the value of knowledge, and the values of scientific inquiry.

\section{Extracurricular work of students}

We organized practical work during the curators' hours. We used the following forms and methods: excursions, collective outputs in cultural institutions, events, and meetings with interested parties (Gabdrakhmanova \& Khuziakhmetov, 2014). Joint work of the teaching staff of first year students and curators is effective and brings a significant contribution to the formation of the personality of the student.

In the framework of curators' hours, we conducted psycho-pedagogical training on the emotional literacy of students on the basis of general observation. We based this on the following assumptions: a fundamental condition for the development of positive emotions in first-year students, future teachers of mathematics, is the awareness of the need to transform his inner world and search for opportunities for self-fulfillment in the learning process, i.e., development of self-assessment, emotion and reflection. Then a conversation that promotes empathy, "immersion" of first-year students in an atmosphere of emotion and morality was approved. For example, the lessons' theme was: "story, a fairy tale, a parable, a metaphor ....", "Culture of behavior" 
and others. These studies have enriched the students with knowledge about the emotional states and their influence on others, contributed to the development of observation, skills of reflection and control over their emotions. Consequently, the value of the educational dialogue lies in the harmony of form and content, the unity of emotional and rational.

We undertook a series of studies that have helped to form the value of knowledge and values of scientific research, as the focus was on the development of criteria such as cognitive needs, the needs of self-realization and the corresponding motives, namely the importance of the subject for training, interest in a particular branch of knowledge, the difficulties of mastering this subject and others.

This formative experiment showed that in the process of adaptation of the first year students, significant changes in relation to the values of education were noted. Criteria for the development of levels of the educational value of dialogue, values of knowledge and values of scientific research make it possible to determine the level of formation of values of education in first-year students, future school teachers (Khuziakhmetov, 2012).

\section{The progress and results of the experiment}

As an experimental group, Mathematics and a foreign language (MA) group were selected. Students of this group had low levels of formation of educational values and achievement in special disciplines. The control group contained students studying for a degree in Mathematics and Computer Science (MI), and, according to the established criteria, were considered to be slightly different from the group "MA".

In the course of the experiment, the selected diagnostic methods, according to our data, showed that $64 \%$ of first-year students have the low level formation of values of education, $21 \%$ have an average level, and only $15 \%$ of first-year students have the necessary level of the tested values.

A compile of the data at the end of the experiment, comparing the performance levels of formation of values of education in first-year students, we found that the experimental group, when compared with the control group, had a significantly increased number of students who achieved a high level $(15 \%)$, and the number of students with low (32\%) formation of values of education decreased. Achieving positive results ensures the integrity of the system of conditions we developed. Empirical data shows that after the experiment parameters values, educational dialogue, values and knowledge of the value of scientific research have become increasingly important for the statistical study of subjects received during the experiment, and that data shows that under the influence of the work carried out by the students, all the studied parameters on aggregate have significantly changed. As a result of educational activities aimed at the formation of values of education among first-year students, the level of significance of the value of education increased, the students evaluated the need for interaction, self-esteem, education, and to acquire significant motives to research activities.

According to the study, we reached the following conclusions:

Essence of the educational values lies in realization of the importance of the acquired knowledge and skills, the need for and feasibility of personal aspirations for quality education. Specificity values of education were found, consisting of a set of values such as the value of educational dialogue, and knowledge of the value and worth of scientific research.

Indication of the value of educational dialogue is interaction, expression of emotions and feelings; indication of the value of knowledge is self-esteem; indication of the value of scientific research is the need for education and motivation in science that track the formation of the studied values. Maturity of values of education is manifested in the low, medium, high levels. 
Model of educational values were defined for first-year students, future teachers of mathematics, in the process of adaptation to studying at university. It consists of the following structural components: the interaction of students, teachers, and curators as subjects of the educational process; task; principles; and the value of education, conditions and results.

We identified a set of conditions for ensuring the effectiveness of the model of formation of values education first-year students, future teachers of mathematics, in the process of adaptation to studying at university. The set of conditions includes: implementation of the formation of educational values focused and integrated in the educational process of high school; accounting of students awareness of their own achievements; inclusion in the process of adapting the various forms of work with students; activation of the immediate social environment of first-year students in the process of teaching and educational activities aimed at developing a common strategy for the formation of educational values.

The experimental work has proven the efficiency of the proposed model; guidelines have been developed for the formation of values of education in first-year students, future teachers of mathematics, in the process of adaptation to studying at university.

\section{DISCUSSIONS}

Questions about the educational values are considered by many teachers, because these questions are always relevant. Reliability and validity of the study have been assured due to the application of modern research methodology using historical and philosophical, psychological, pedagogical and methodological sources; rational use of methods of theoretical and experimental studies; wide testing and implementation of the results of the university into practice.

Analysis of the literature and many years of empirical experience teaching activities suggest that in the modern theory and practice of higher education, not enough attention has been paid to the formation of educational values of first-year students in the process of adaptation to studying in university. Increasing attention towards pedagogical issues of formation of educational values of students has been explained by the difficult implementation of the practical side of the problem in the contemporary socio-economic conditions (Khuziakhmetov, 2011). This problem is not sufficiently developed in the context of the educational activities of universities. Therefore, it is necessary to develop educational values of first-year students in the process of adaptation to their studying at university, and also necessary to pay attention to the work of teachers of university, as well as the work of curators, because they are among the first to introduce first-year students in the field of educational activities of the university (Khuziakhmetov \& Gabdrakhmanova, 2011).

\section{CONCLUSION}

According to the results of research, the following conclusions were reached:

1. Specificity of education values was determined. This specificity consists of a set of values such as the value of the educational dialogue, knowledge of the value and worth of scientific research.

2. Indication of the value of the educational dialogue is interaction, expression of emotions and feelings, an indicator of the value of knowledge is self-esteem, giving a value of scientific research is the need for education and motivation in science that track the formation of the studied values.

3. The complex conditions were observed to ensure the effectiveness of the formation of values education of first-year students, future teachers of mathematics in the process of their adaptation to studying at university. The 
complex includes: implementation of formation of educational values targeted in the educational process of high school; accounting students' awareness of their own achievements; inclusion in the process of adapting the various forms of work with students; activation of the immediate social environment of first-year students in the educational work.

\section{RECOMMENDATIONS}

\section{For researchers}

The materials of this article will be of interest to researchers of problems related to the organization of educational processes in higher education. It is important for researchers to pay attention to the organizing and conducting of experiments.

We have to focus on a persons' aspiration for a quality education, and the degree of the importance of the awareness of students' to acquire their own knowledge and skills.

\section{For practitioners}

The materials of this article will be of interest to curators of student groups, university teachers, and heads of departments. These materials can be used in their work with first-year students in higher education.

\section{ACKNOWLEDGMENTS}

This study has been performed according to the Russian Government Program of Competitive Growth of Kazan Federal University

\section{REFERENCES}

Gabdrakhmanova, R. G., \& Egereva, S. F. (2012). Multiprofessional approach to anti-drug education for young people as a factor of self-identity. Education and self-development, 4 , 126-131.

Gabdrakhmanova, R. G., \& Khuziakhmetov, A. N. (Eds.), (2014). The work of the teacher on the cultural socialization of students: Theoretical and applied education and science. Tambov.

Ilyinsky, I. M. (2011). Where does home education go? Students. Dialogues about upbringing, 55, 4-6.

Khusainova, R. M., Chirkina, S. E., \& Gabdrakhmanova, R. G. (2015). The Role of the Reflective Activity of Students in Individual Educational Trajectory. Review of European studies, $7(5), 146-152$.

Khuziakhmetov, A. N. (2004). Value potential of pedagogical influence. Higher Education in Russia, 12, 108-112.

Khuziakhmetov, A. N. (2005). To bring up patriots. Higher Education in Russia, 6, 115-119.

Khuziakhmetov, A. N. (2006). Theory and methods of education. Kazan, Magarif.

Khuziakhmetov, A. N. (2009). Pedagogical technologies. Kazan, Magarif.

Khuziakhmetov, A. N. (2011). Socio-pedagogical movement in Russia: the moral and educational paradigm. Moscow, Moscow. School Press.

Khuziakhmetov, A. N. (2012). Problems of socialization of the person in educational theory and practice. Education and Self-development, 30, 121-127.

Khuziakhmetov, A. N., \& Gabdrakhmanova R. G. (2011). Socialization of the personality of student: problems, searches, solutions. Kazan, Magarif.

Nigmatov, Z. G. (2014). Humanitarian technologies of inclusive education. Procedia-Social and Behavioral Sciences, 131, 156-159.

Nigmatov, Z. G. (2015). Methodic techniques of solving technical problems developing technical students' thinking. Review of European Studies, 7(1), 171-175.

Plaksiy, S. (2007). Experience in building the strategy of the university, 7, 78-81.

Yarullin, I. F., \& Nasibullov, R. R. (2014) Formation of future teacher's civil responsibility in the contemporary society. Life Science Journal, 11, 311-315. 
Zaripova, I. M., Merlina, N. I., Valeyev, A. S., Upshinskaya, A. E., Zaripov, R. N., Khuziakhmetov, A. N., \& Kayumova, L. A. (2015). Methodological support for professional development of physical-mathematical sciences teachers, aimed at forming the project-technical competency of technical university students. Review of European Studies, 7(3), 313-318. 